\title{
Surgical Treatment of Chronic Subdural Hematoma: Clinical Characteristic, Surgical Outcome, Complication and Recurrence Rate
}

\author{
Dr. Vipul Kumar Gupta ${ }^{1}$, Dr. Akshay Gupta ${ }^{2}$ \\ ${ }^{1}$ Consultant Lect. Department of Neurosurgery, GMC Jammu \\ ${ }^{2}$ Postgraduate Student Department of Surgery, GMC Jammu \\ *Corresponding Author: Dr. Akshay Gupta; aksheye.gupta@gmail.com
}

Received 28 March 2021;

Accepted 20 April 2021;

Published 14 May 2021

\begin{abstract}
Background: Chronic subdural hematoma is one of the most frequent neurosurgical conditions encountered in elderly people (usually, after minor head trauma) and in patients on long term anticoagulation and long term hemodialysis. The aims of this study is to evaluate the clinical characteristics found in chronic subdural hematoma patients \& the surgical outcomes, complications and recurrence rate in chronic subdural hematoma patients. Method: A prospective study of surgical treatment of chronic subdural hematoma, clinical characteristics, surgical outcomes, complication and recurrence rate was done over a period of 2 months between $1^{\text {st }}$ June, 2020 and $31^{\text {st }}$ July, 2020 at GMC Jammu. Result: A total of 35 patients of chronic subdural hematoma, 28 males and 7 females underwent surgery. Maximum were in the age group range of 66-70 years and 81-85 years. 20 cases developed SDH after trauma (due to fall) and 15 cases developed spontaneous SDH. The most common presenting complaint of patients seen in our study was hemiplegia/hemiparesis in 26 cases followed by headache in 15 cases. 10 cases were found to have bilateral hematoma. The most common post-operative complication observed was reaccumulation of hematoma seen in 4 cases. In our study out of 35 patients 27 had GCS score of 15 . These patients were discharged home earlier post-operatively, with good outcome. Surgical outcome was good in $100 \%$ cases \& $0 \%$ surgical mortality was observed. Conclusion: Burr hole evacuation for chronic subdural hematoma provides significant improvements is neurological status and good outcomes with $0 \%$ mortality observed in our study.
\end{abstract}

\section{Introduction}

Chronic subdural hematoma is one of the most frequent neurosurgical conditions. It is frequently encountered in elderly people (usually, after minor head trauma) and in patients on long term anticoagulation and long term hemodialysis.

It is due to rupture of veins between dura and brain (cerebral hemisphere) and there is gradual collection of blood in subdural space. Usual hematoma collection is $60-120 \mathrm{ml}$. Subdural hematomas are divided into acute, subacute and chronic types. Acute hematomas are those that are clinically evident within 72 hours of accumulation, chronic hematomas present over 20 days and subacute hematomas are detected between 3 days and 3 weeks.

The annual incidence of chronic subdural hematoma has been estimated at 1.7 per 100,000 population (Fogelholm et al 1975b). Males outnumber females by a ratio of 2 or $3: 1$ (McKissock et al 1960; Baechli et al 2004). Two age groups are most at risk of developing chronic subdural hematoma: the young and the elderly. Advanced age and chronic alcoholism are common antecedents, presumably because of brain atrophy, which causes stretching of bridging veins and thus predisposes to tearing. Recently implanted CSF shunts, CSF fistulae, coagulopathy, bone marrow transplantation, arachnoid cysts, renal dialysis, vascular malformations and seizures have been reported to predispose to chronic subdural hematoma formation. The risk of intracranial hemorrhage is increased 13 times in women and 4 times in men who are receiving anticoagulation.

$15-20 \%$ of chronic subdural hematomas are bilateral (McKissock et al). They tended to occur more in patients with anticoagulant or antiplatelet therapy (Tsai et al 2010). Bilateral chronic hematoma is common in patients with symmetrical frontal and occipital cranial vault. In asymmetrical cranium, chronic subdural hematoma is usually present on the same side of the most curved frontal and occipital convexity (Akhaddar et al, 2010).

One day after the initial hemorrhage, the outer surface of the hematoma is covered with a thin layer of fibrin, and fibroblasts begin to migrate towards the clot. This migration increases, and the fibroblasts proliferate so that by the 4th day a membrane 3-4 cells thick is present on the outer surface of the clot. Over the next week, the outer membrane progressively enlarges, and fibroblasts begin to invade the hematoma itself. A thin inner membrane of fibroblasts is present after 2 weeks. The lack of counter-pressure in predisposed patients may permit growth of a small hematoma that might otherwise resolve spontaneously (LEE et al 1998; Maurice Williams 1999). 
The second mechanism for subdural hematoma growth is recurrent bleeding from the hematoma capsule (Putnam and Cushing 1925; Ito et al 1987).

Enhanced synthesis of extracellular matrix component following meningeal trauma may also contribute to chronic subdural hematoma formation (Sajanti and Majamaa 2003).

The most frequent presenting symptoms are headache, cognitive decline, gait abnormalities and hemiparesis. Headache occurs in $30-90 \%$ cases. At times the headache is described as mild and generalizes; however, in three-fourth cases, at least one of the following features is present: sudden onset, severe pain, exacerbation with coughing, straining, or exercise, nausea and vomiting. Altered mental status is a frequent complaint. Although this may manifest as mild confusion or dementia, the changes may be more profound and the patient may have a markedly decreased level of consciousness or may even be obtunded. Mental status changes are probably responsible for the labelling of many patients with chronic subdural hematomas as suffering from psychiatric disease. Hemiparesis is also a common presenting complaint, and the neurologic dysfunction is usually contralateral to the hematoma; however at times it may be ipsilateral.

Chronic subdural hematomas occasionally present as transient ischemic attacks. When this occurs, the average duration of neurologic dysfunction is 30 mins and the patient most commonly experiences aphasia, hemiparesis, or a hemi-sensory deficit. Epilepsy is the initial symptom in $3-11 \%$ of patients with chronic subdural hematomas. Lower mean Glasgow Coma Scale score was found independently predictive of seizures in patients with subdural hematoma; seizures frequently occurred within the first three months of illness. Chronic subdural hematoma occasionally present with varied extrapyramidal manifestations like choreoathetoid movement and parkinsonism (Lilang et al 2002).

The diagnosis of traumatic intracerebral hematoma is made quickly and accurately with CT or MRI. The chronic hematoma is dynamic; therefore, its appearance on CT is dependent on the phase of development. In the week after the initial hemorrhage, the acute blood is hyperdense to the normal brain, then generally isodense to normal brain for a period of 1-3 weeks after the initial bleed, and finally hypodense after 3 weeks in the chronic phase. Isodense hematomas may be detected indirectly, that is, by evidence of mass effect manifested by sulci displacement, deformation of the ventricular anatomy and obliteration of the cisterns. Sometimes differentiation of subacute hemorrhage and chronic hemorrhage is difficult with CT, then MRI is the informative and precise study (William and Hogg 2000).

Advocates for medical management of chronic hematoma have not been convincing (Bender and Christoff 1974), failures are common (Gjerris and Schmidt 1974), and most comparisons strongly favor surgical drainage. Not only is the outcome better, but hospital stay and expenses are also less.

Chronic hematomas have been evacuated by craniotomies, burr holes and twist drill craniotomies. Burr hole location is guided by hematoma size and shape. The patient is positioned on the table with the affected side up (for bilateral hematomas both sides of the head are draped and the larger one is drained first). Two holes suffice in most cases; frontal and parietal placement at the anterior and posterior margins of the collection usually works well. The dura over the anterior burr hole is opened first to prevent premature collapse of the subdural space. On opening the dura, a thick outer hematoma membrane is encountered. The composition of hematoma varies with the age of the blood, from fresh clot to thin xanthochromic fluid. In most cases the hematoma has an intermediate appearance and has been described as resembling crankcase oil. If intracranial pressure is high, considerable fluid leakage occurs and the brain often re-expands. Irrigation is recommended for residual fluid; catheters with multiple fenestrations are gently threaded into subdural spaces and irrigated by gravity until the return fluid is clear. Evacuation and closed drainage through a twist drill hole is simple, safe and effective (Tabaddor and Shulman 1977).

The most common post-operative complications encountered are:

- Reaccumulation of hematoma

- Subdural empyema

- Putaminal hemorrhage

- Cerebral Infarction

- Pneumocephalus

- Epilepsy

- Meningitis

- Coning

Medical complications such as pneumonia, ileus, DIC are common postoperatively especially in the elderly and debilitated (Rhode et al 2002).

The most common and vexing postoperative problem is that of accumulation of subdural hematoma; the risk is about $15 \%$ (Tindall et al 1976; Baechli et al 2004). Recurrence has been reported to be more common when the collections appear isointense or hypointense to brain on preoperative T1-MRI images (Tsutsumi et al 1997). It is also more likely in wider hematomas and less likely when there are multiple cavities (Yamamoto et al 2003; Stanisic et al 2005). Univariate and multivariate analysis found that bilateral chronic hematoma was an independent risk factor for the recurrence of hematoma. Another multivariate regression analysis identified the number of holes as an important predictor for postoperative recurrence (Taussky et al 2008).

Factors which lead to recurrence are:

- $\quad$ Skin subdural hematoma

- Anticoagulant therapy

- Brain re-expansion

- Pneumocephalus

- Intracranial hypotension

- $\quad$ Surgical techniques

The outcome of patients with chronic subdural hematoma is variable. Reported mortality ranges between $0 \%-40 \%$ with older series reporting about 10\% (McKissock et al 1960; Markwalder 1981). Outcome is closely related to patient's neurological function at the time of operation, medical status and age (Missori et al 2000; Gelabert-Gonzalez et al 2005), patients older than 50 years of age have a 5-fold higher mortality. In one study, it was noted that the factors that determined mortality include age, Glasgow Coma Scale score at presentation and associated illnesses like cardiac and renal failure (Ramchandran and Hegde 2007). In the Cox proportional hazards model, only age and discharge to home were related to survival, whereas the type of intervention, whether surgery was performed, size of hematoma, amount of shift, bilateral subdural hematomas and anticoagulant agent use did not affect the long or short term mortality rate (Miranda et al 2011).

The overall causes of mortality are:

- Age

- CVS disease in elderly

- Coagulopathy 
- Cerebral Infarction

- Putaminal hemorrhage

- Acute epidural hemorrhage

- Subdural empyema

\section{Aim}

The aims and objectives of the present study is to evaluate the:

- Clinical characteristics found in chronic subdural hematoma patients.

- The surgical outcomes, complications and recurrence rate in chronic subdural hematoma patients.

\section{Materials and Methods}

A prospective study of surgical treatment of chronic subdural hematoma, clinical characteristics, surgical outcomes, complication and recurrence rate was done over a period of 2 months between $1^{\text {st }}$ June, 2020 and $31^{\text {st }}$ July, 2020 at GMC Jammu.

After initial resuscitation; detailed history and physical examination were taken followed by laboratory investigations.

\section{Laboratory Investigations:}

- Complete blood counts

- Prothrombin time and activated partial thromboplastin time

- Blood urea, serum creatinine, $\mathrm{Na}+, \mathrm{K}+$, blood sugar

- $\quad$ Blood typing

Imaging Studies:

- CT Scan

$$
\begin{array}{ll}
\circ & \text { Plain } \\
\circ & \text { Contrast }
\end{array}
$$

- $\quad$ MRI

Treatment:

- Pre-operative resuscitation

- Nil per mouth

- Intravenous line
- Antibiotics

- Anticonvulsants

- Antacids

- Analgesics

- Catheterisation

CT indications for surgery:

- Chronic SDH with mass effect

- Midline Shift

\section{Surgical Management:}

All cases were operated in Neurosurgery OT

- Locally part preparation done

- Administration of local analgesic and some sedation.

- Oxygen via face mask

- Intravenous line to be secured

- Burr hole evacuation done (Parietal only or Parietal and Frontal)

- Dura opened in + fashion

- Flaps coagulated

- Cavity washed with normal saline till clear saline flows out by pushing saline from frontal burr hole

- If only parietal burr hole is made; cavity is washed after placing a F-8 feeding tube

- Layers of skull stitched back

\section{Post-operative Care:}

- Antibiotics

- Antiepileptics

- Analgesics

- Bed rest for 72 hours

- Ambulate the patient after 72 hours

- Sutures removed on 8 th post-operative day and discharged

- Repeat CT Scan post-operatively if there is a deterioration in neurological status

\section{Results}

Table 1: Mean age, sex ratio

\begin{tabular}{|l|l|}
\hline Age (Range) & $45-90$ years \\
\hline Mean Age & 71 years \\
\hline Males & 28 \\
\hline Females & 07 \\
\hline Ratio (males:females) & $4: 1$ \\
\hline
\end{tabular}

A total of 35 cases were studied out of which 28 were males and 7 were females making a male:female ratio of 4:1.

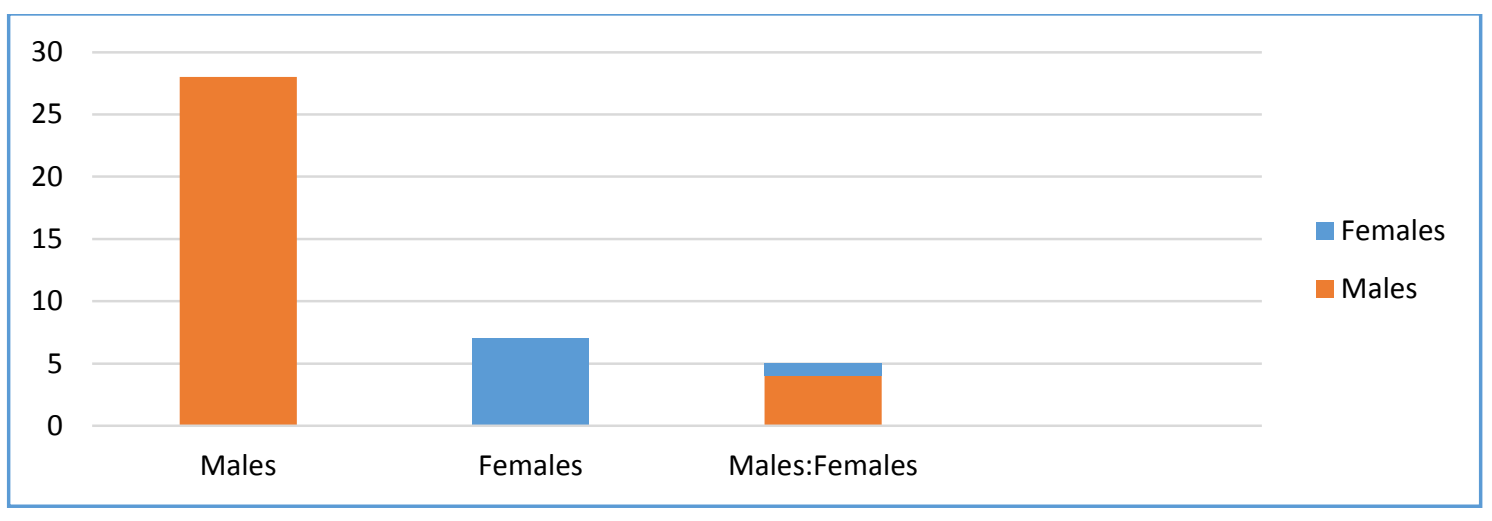

Fig. 1 
Table 2: Age incidence in relation to mortality

\begin{tabular}{|l|l|l|}
\hline Age (Years) & No. of Cases & Mortality (\%) \\
\hline$>45$ & 00 & 00 \\
\hline $46-50$ & 01 & 00 \\
\hline $51-55$ & 02 & 00 \\
\hline $56-60$ & 04 & 00 \\
\hline $61-65$ & 03 & 00 \\
\hline $66-70$ & 08 & 00 \\
\hline $71-75$ & 04 & 00 \\
\hline $76-80$ & 05 & 00 \\
\hline $81-85$ & 08 & 00 \\
\hline$>86$ & 00 & 00 \\
\hline Total & $\mathbf{3 5}$ & $\mathbf{0 0}$ \\
\hline
\end{tabular}

Mean age of patients admitted was 70.42 years. The most number of patients were in the 66-70 years and 81-85 years old groups.

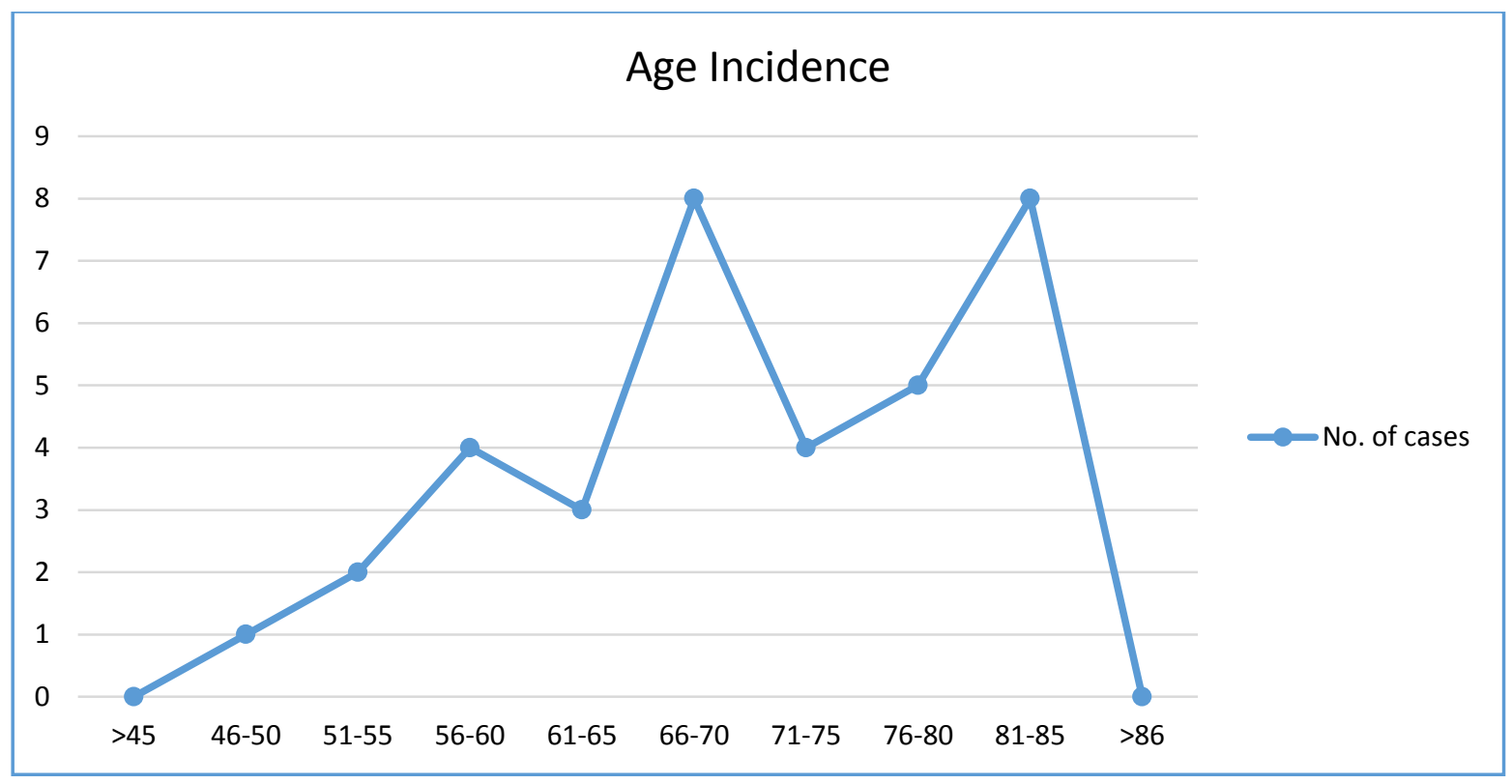

Fig. 2

Table 3: Incidence of traumatic and spontaneous Chronic SDH

\begin{tabular}{|l|l|l|}
\hline & Trauma & Spontaneous \\
\hline No. of cases & 20 & 15 \\
\hline$\%$ & 57.14 & 42.86 \\
\hline
\end{tabular}

Accidental falls account for $57.14 \%$ of the cases in the development of SDH. Rest of the cases developed spontaneous chronic subdural hematoma.

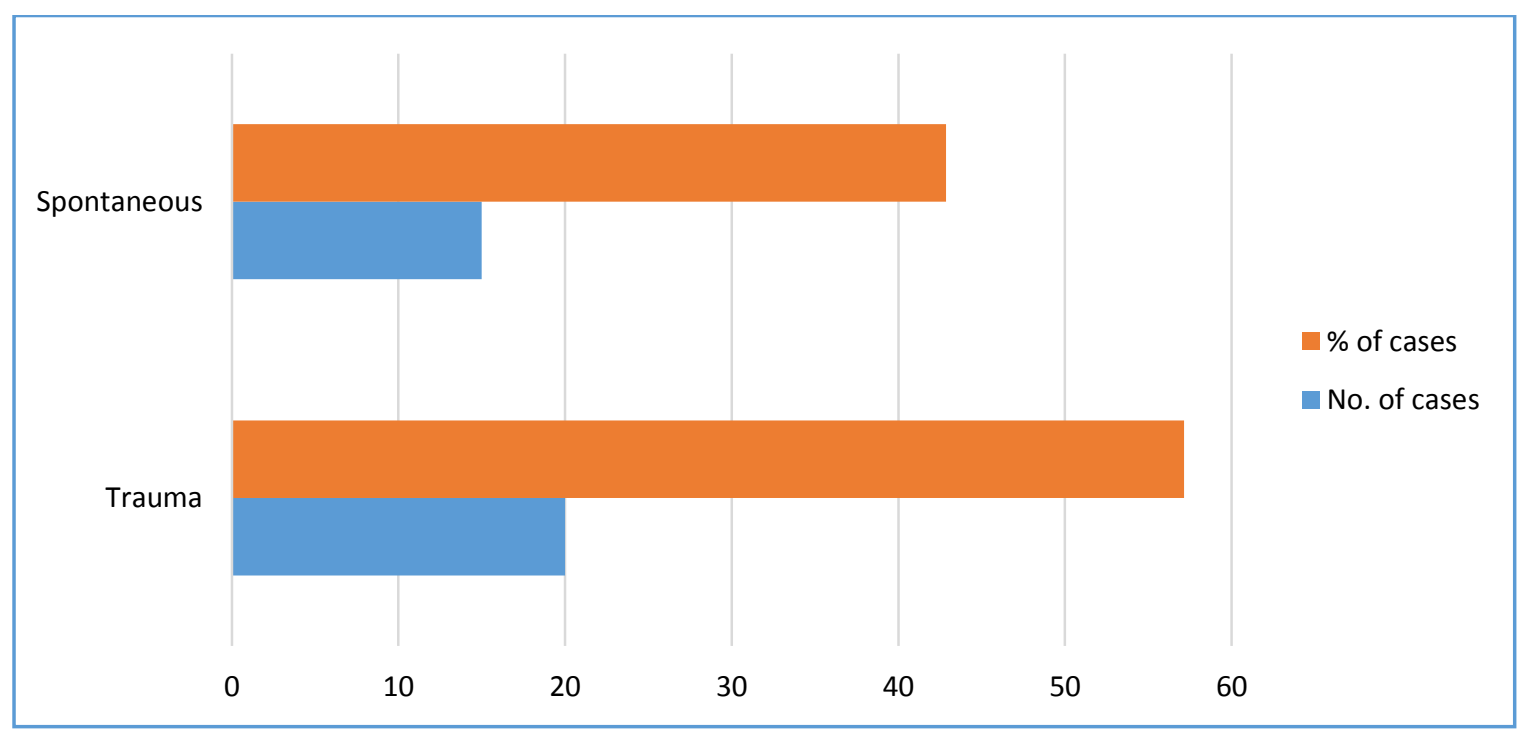

Fig. 3 
Table 4: Various presentations in patients with SDH

\begin{tabular}{|l|l|l|}
\hline Clinical Features & No. of cases & \% of cases \\
\hline Headache & 15 & 42.8 \\
\hline Weakness in part/parts of body & 26 & 74.2 \\
\hline Difficulty in speech & 14 & 40 \\
\hline Seizure & 03 & 8.5 \\
\hline Difficulty in walking & 18 & 51.4 \\
\hline Memory Deficit & 02 & 5.7 \\
\hline
\end{tabular}

In majority of the patients, there was a history of weakness of one half of the body or whole body. It was observed in 26(74.2\%) cases. Headache was complained of in 15(42.8\%) cases, mostly frontal. 18(51.4\%) patients experienced difficulty in walking. 14(40\%) cases had difficulty in speech. $3(8.5 \%)$ cases experienced seizures whereas memory deficit was complained of in $2(5.7 \%)$ cases.

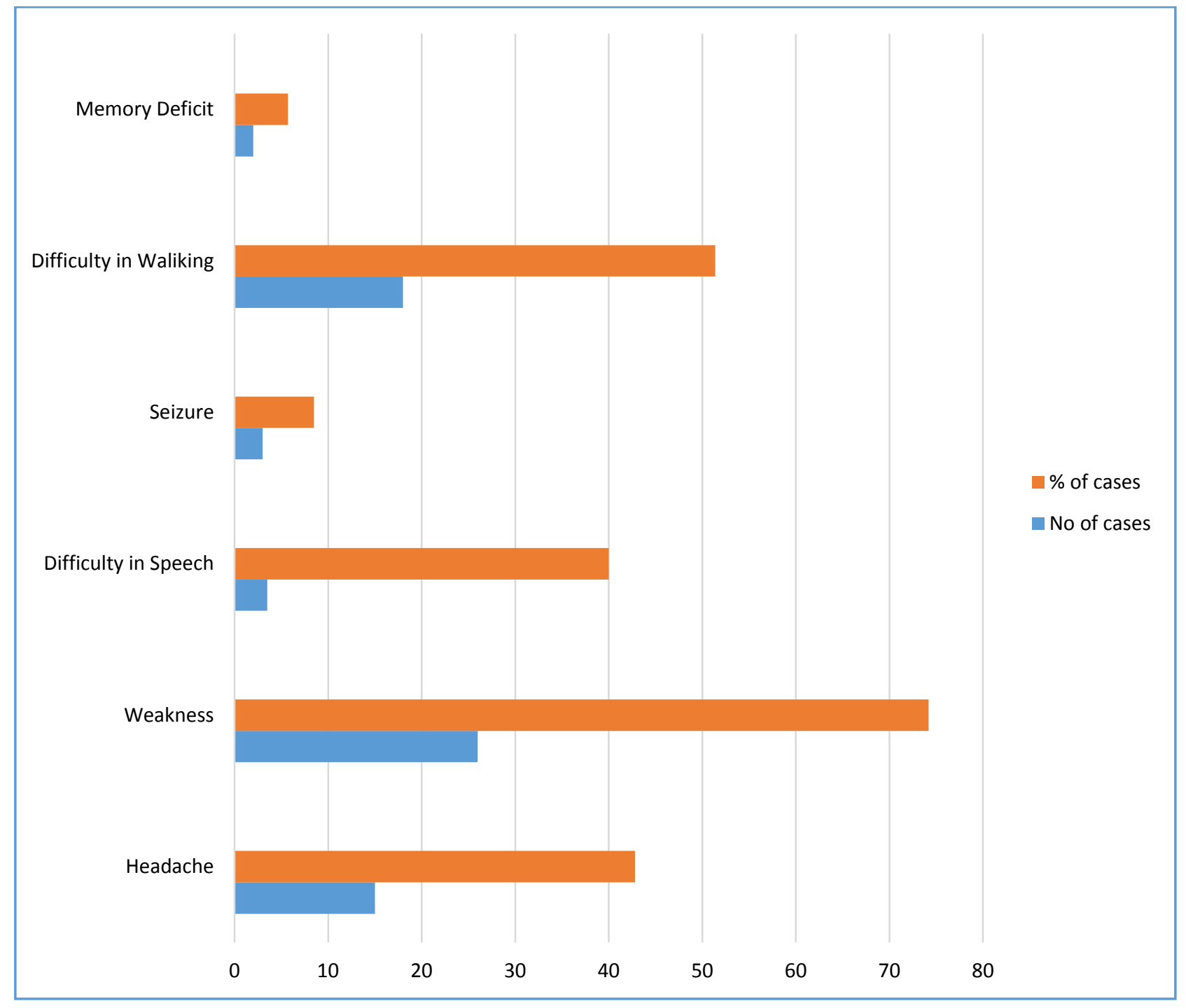

Fig. 4

Table 5: GCS score with respect to outcome and mortality

\begin{tabular}{|l|l|l|l|l|l|l|}
\hline GCS score & No. of cases & \multirow{2}{*}{$\%$ of cases } & Outcome & No of deaths & \multirow{2}{*}{ \% of deaths } \\
\cline { 3 - 6 } & & & Good & Poor & & \\
\hline$<5$ & 01 & 2.8 & 1 & 0 & 0 & \\
\hline $5-7$ & 00 & 00 & 0 & 0 & 0 & 0 \\
\hline $8-10$ & 04 & 11.5 & 4 & 0 & 0 & 0 \\
\hline $11-13$ & 03 & 8.5 & 3 & 0 & 0 & 0 \\
\hline$>13$ & 27 & 77.2 & 27 & 0 & 0 & 0 \\
\hline
\end{tabular}

27 cases were reported with a GCS score of $>13$. Four patients had score of 10. Three patients had a score of 13. One patient had GCS score of 4. All cases were operated with good outcome with no mortality. 


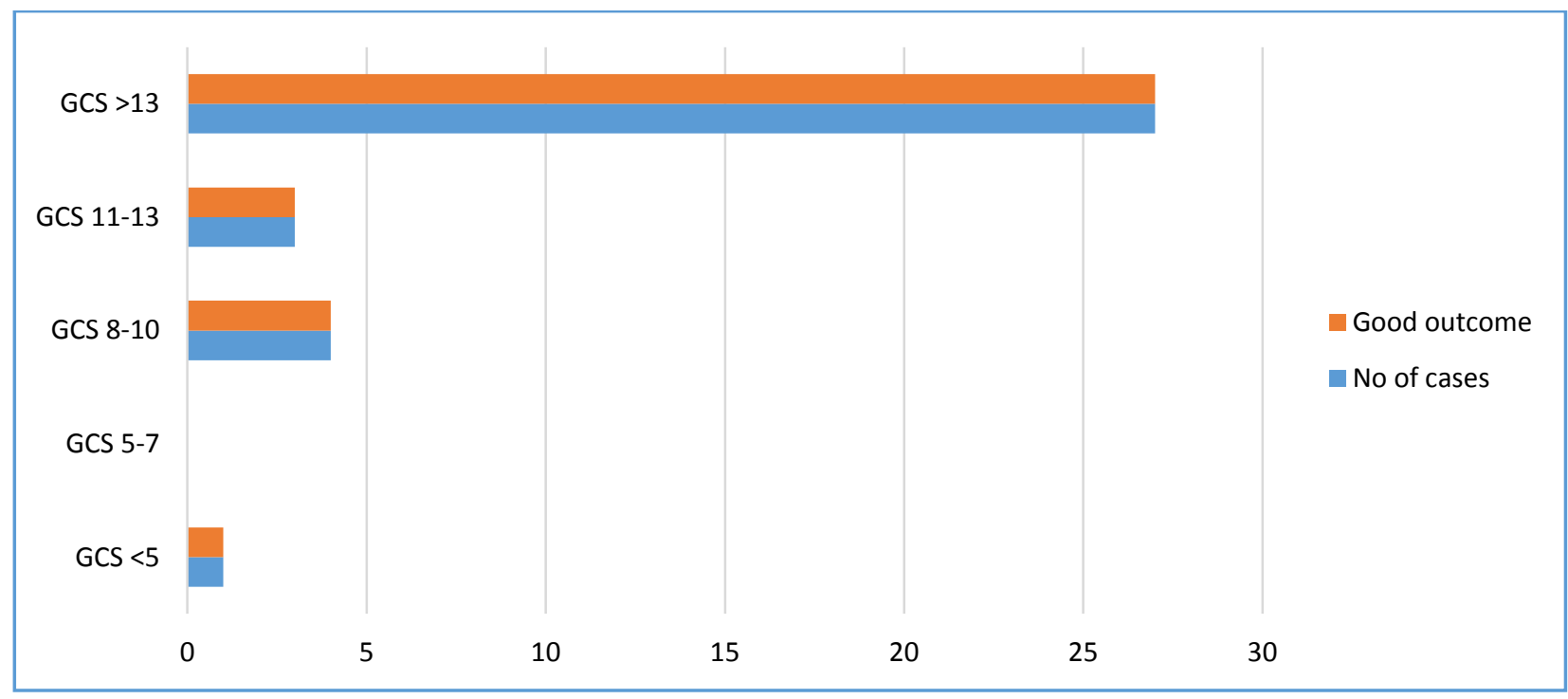

Fig. 5

Table 6: Outcome and mortality in relation to age

\begin{tabular}{|l|l|l|l|l|l|l|}
\hline Age (years) & No. of cases & \multirow{2}{*}{$\%$ of cases } & Outcome & No. of deaths & \multirow{2}{*}{ of deaths } \\
\cline { 3 - 6 } & & & Good & Poor & & \\
\hline$<70$ & 18 & 51.4 & 18 & 0 & 0 & 0 \\
\hline$>70$ & 17 & 48.6 & 17 & 0 & 0 & 0 \\
\hline
\end{tabular}

$18(51.4 \%)$ patients were $<70$ years of age while 17 (48.6\%) patients were $>70$ years of age. All the cases had good outcome postoperatively with no mortality.

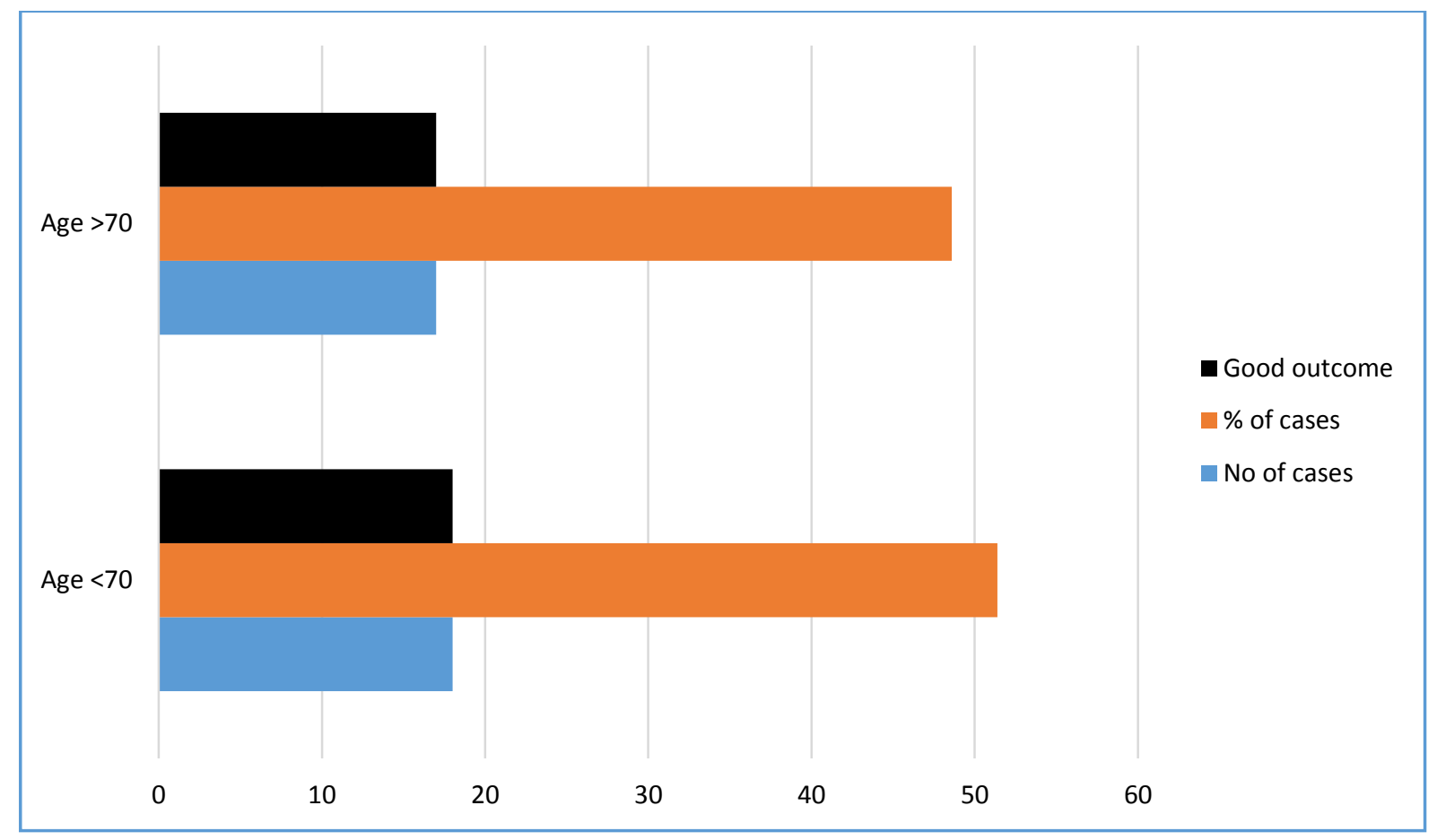

Fig. 6

Table 7: Incidence of unilateral and bilateral SDH

\begin{tabular}{|l|l|l|l|}
\hline \multirow{2}{*}{ No of cases } & Unilateral lesion & \multirow{2}{*}{ Bilateral lesion } \\
\cline { 2 - 3 } & Left sided & Right sided & \\
\hline \% of cases & 18 & 07 & 10 \\
\hline Outcome & 20 & 20 & 28.6 \\
\hline
\end{tabular}

All the cases were scanned by CT to confirm the diagnosis. In 18 cases the lesion was on the left side and in 7 cases the lesion was on the right side. Only 10 (28.6\%) cases had bilateral lesions. In all the 35 cases outcome was good. 


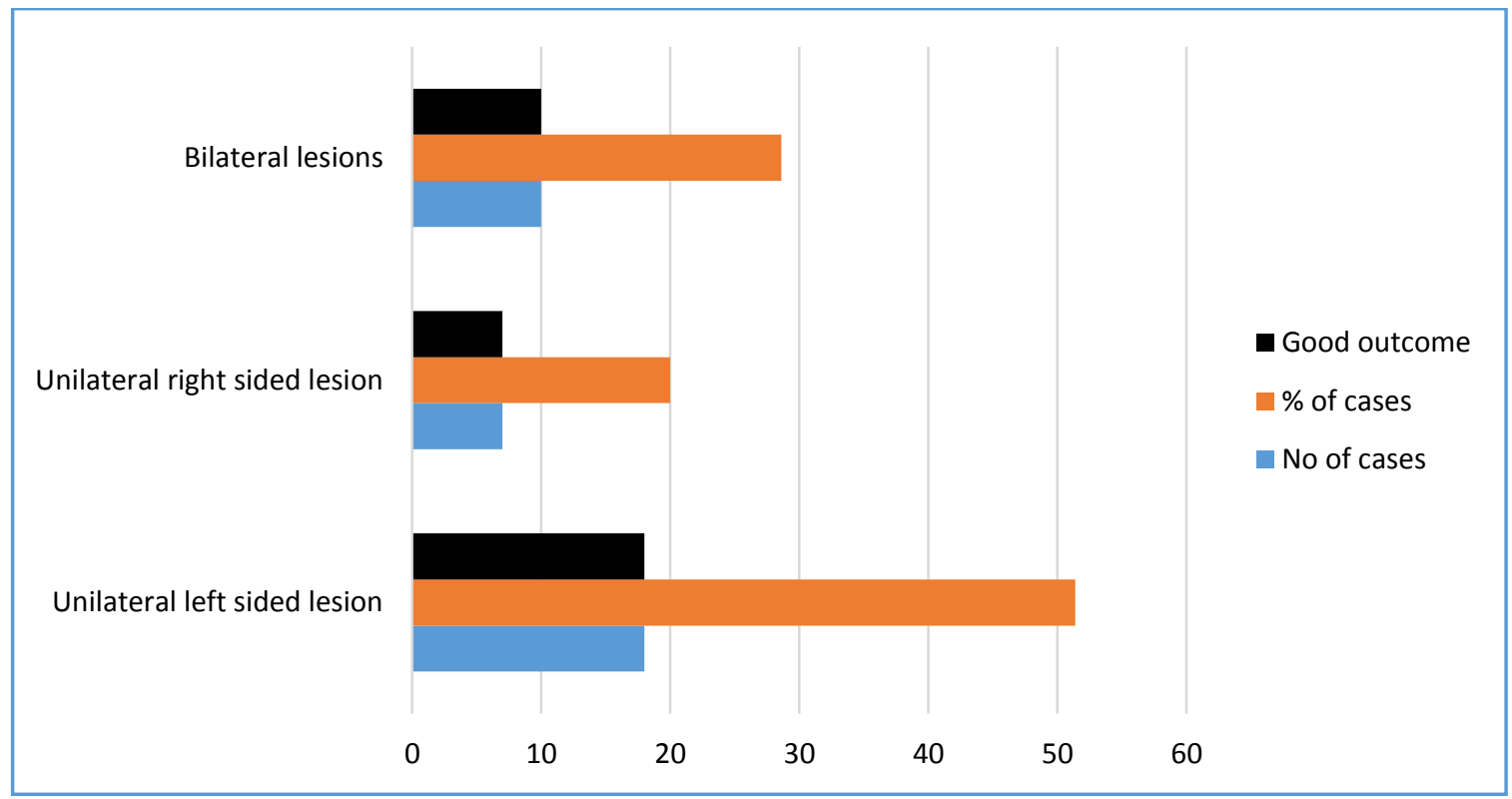

Fig. 7

Table 8: Incidence of various lesions on CT scan

\begin{tabular}{|l|l|l|}
\hline Site of lesion & No. of cases & \% of cases \\
\hline Frontal & 01 & 2.9 \\
\hline Fronto-Parietal & 26 & 74.3 \\
\hline Fronto-Temporal & 02 & 5.7 \\
\hline Fronto-Parieto-Temporal & 04 & 11.4 \\
\hline Fronto-Parieto-Occipital & 02 & 5.7 \\
\hline
\end{tabular}

In our study, 1 hematoma was located in frontal region, 26 hematomas in fronto-parietal region, 2 hematomas in fronto-temporal, 4 hematomas in fronto-parieto-temporal and 2 hematomas were located in fronto-parieto-occipital region.

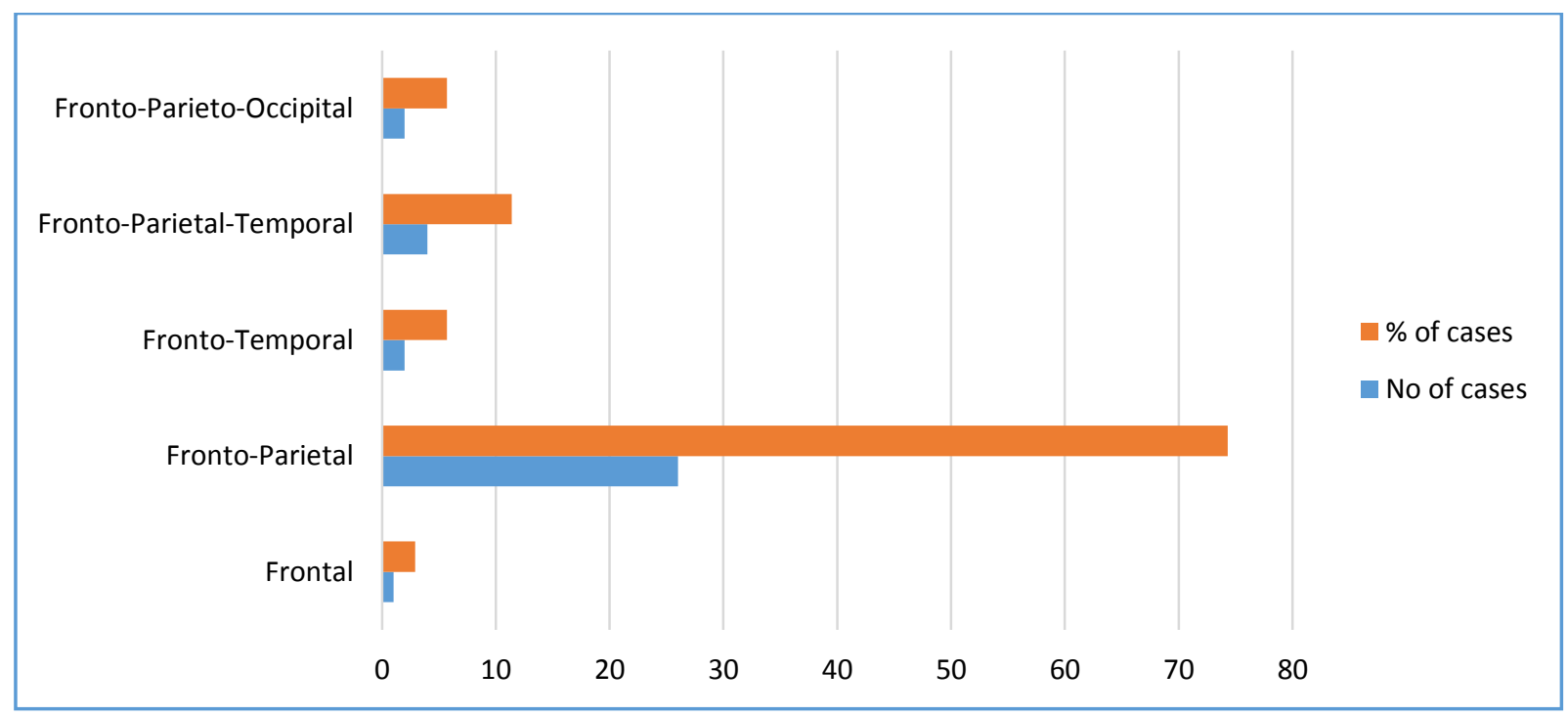

Fig. 8

Table 9: CT scan findings affecting the outcome and mortality

\begin{tabular}{|c|c|c|c|c|c|c|}
\hline \multirow[t]{2}{*}{ Characteristics } & \multirow[t]{2}{*}{ No. of cases } & \multirow[t]{2}{*}{$\%$ of cases } & \multicolumn{2}{|c|}{ Outcome } & \multirow[t]{2}{*}{ No of deaths } & \multirow[t]{2}{*}{$\%$ of deaths } \\
\hline & & & Good & Poor & & \\
\hline \multicolumn{7}{|l|}{ Max Thickness } \\
\hline$>10 \mathrm{~mm}$ & 18 & 51.4 & 18 & 0 & 0 & 0 \\
\hline $10-30 \mathrm{~mm}$ & 12 & 34.3 & 12 & 0 & 0 & 0 \\
\hline$>30 \mathrm{~mm}$ & 05 & 14.3 & 05 & 0 & 0 & 0 \\
\hline \multicolumn{7}{|l|}{ Midline Shift } \\
\hline Present & 20 & 57.1 & 20 & 0 & 0 & 0 \\
\hline Absent & 15 & 42.9 & 15 & 0 & 0 & 0 \\
\hline
\end{tabular}


$18(51.4 \%)$ cases were observed to have $<10 \mathrm{~mm}$ thickness which raised to 30 cases with $<30 \mathrm{~mm}$ thickness having good outcome in all 30 . Good outcome was seen in all 5 patients with $>30 \mathrm{~mm}$ thickness. Midline shift was seen in $20(57.1 \%)$ cases. The overall outcome was good in all cases irrespective of presence or absence of midline shift.

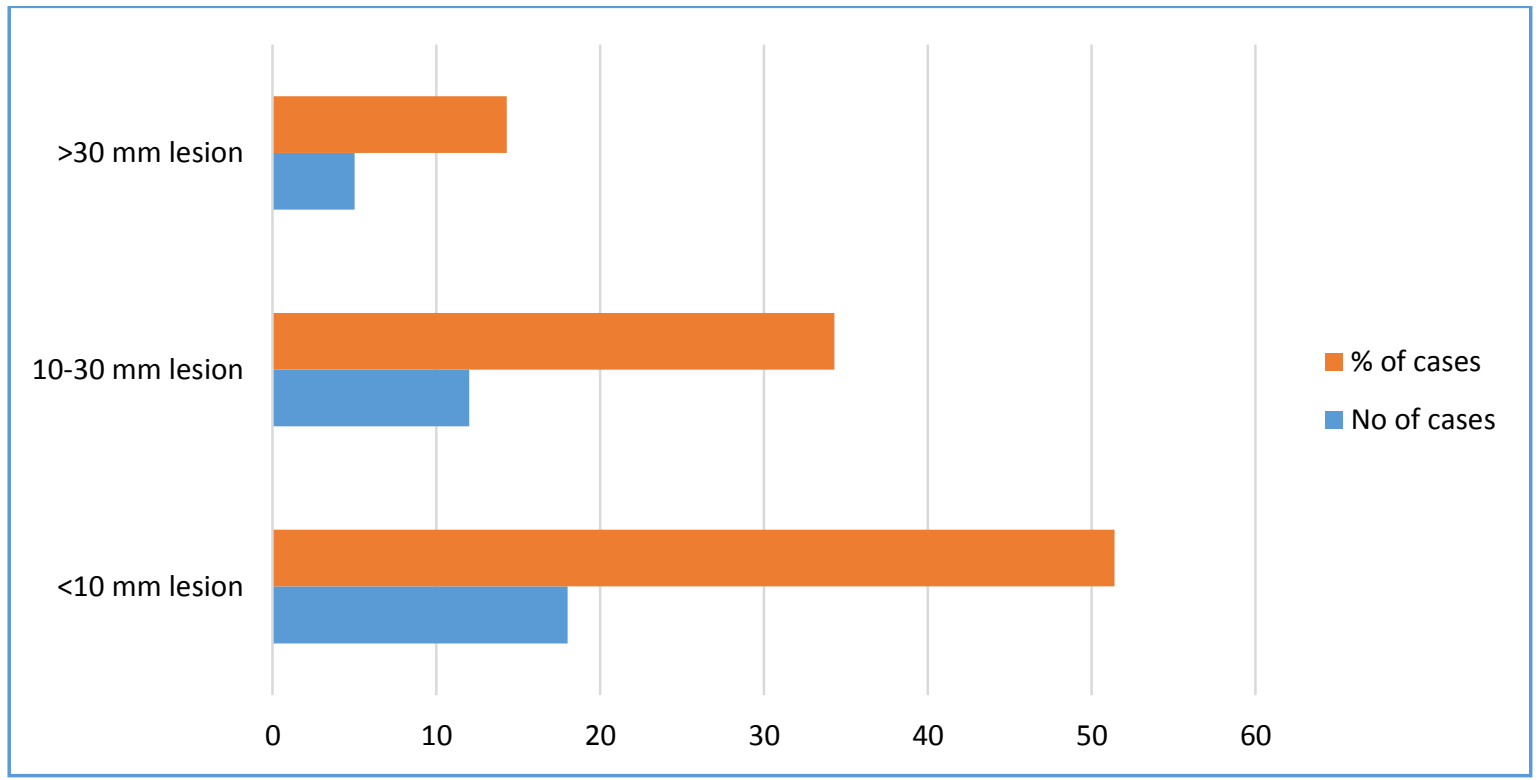

Fig. 9

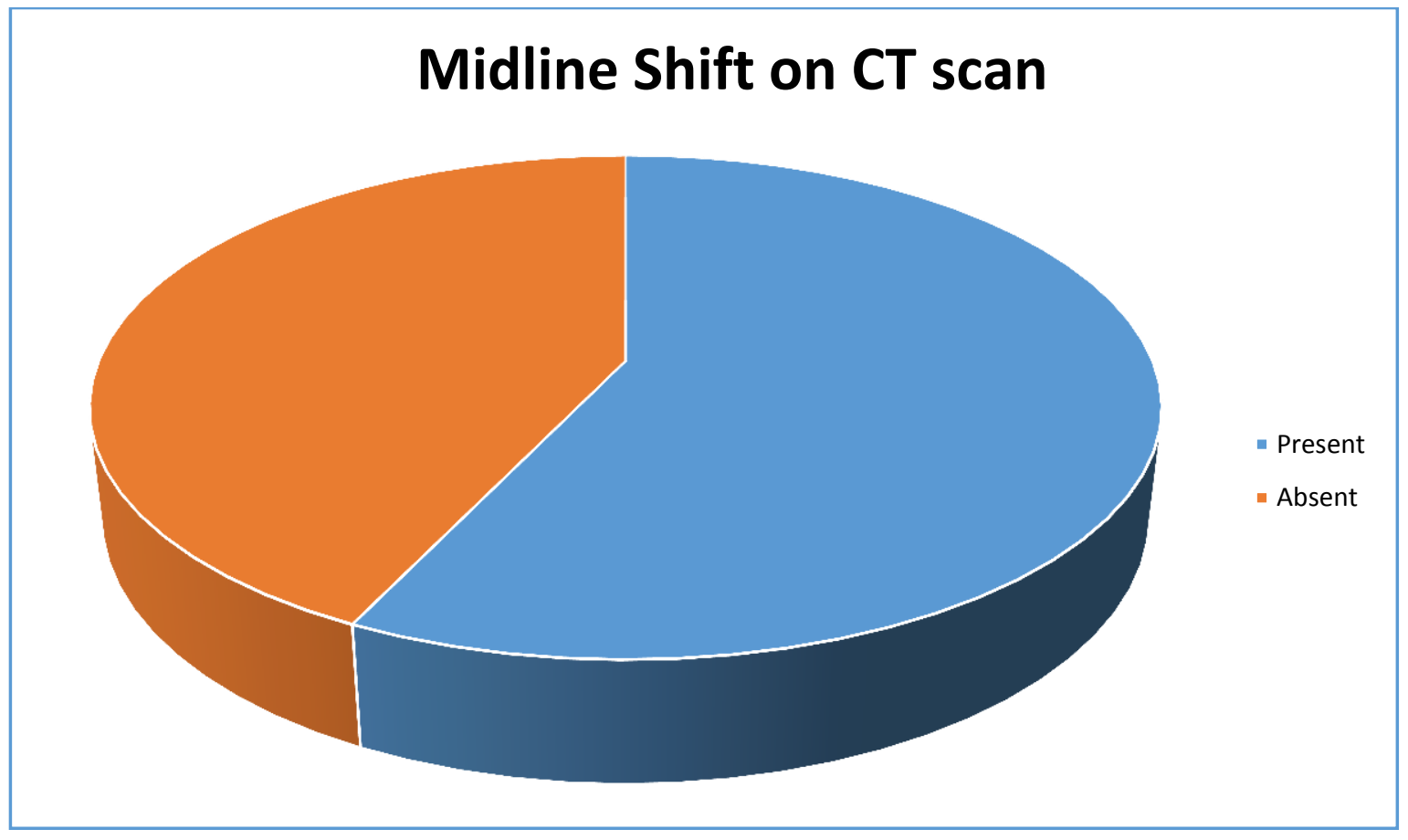

Fig. 10

Table 10: Incidence of post-operative symptoms

\begin{tabular}{|l|l|l|}
\hline Post-op symptoms & No of cases & \% of cases \\
\hline Paresis & 03 & 8.6 \\
\hline Headache & 01 & 2.9 \\
\hline Seizure & 00 & 0 \\
\hline Loss of consciousness & 00 & 0 \\
\hline Difficulty in speech & 00 & 0 \\
\hline Difficulty in walking & 00 & 0 \\
\hline Total & $\mathbf{0 4}$ & $\mathbf{1 1 . 5}$ \\
\hline
\end{tabular}

In our study, the most common post-operative symptom observed was paresis seen in 3 cases $(8.6 \%)$ and headache in $1(2.9 \%)$ cases. 


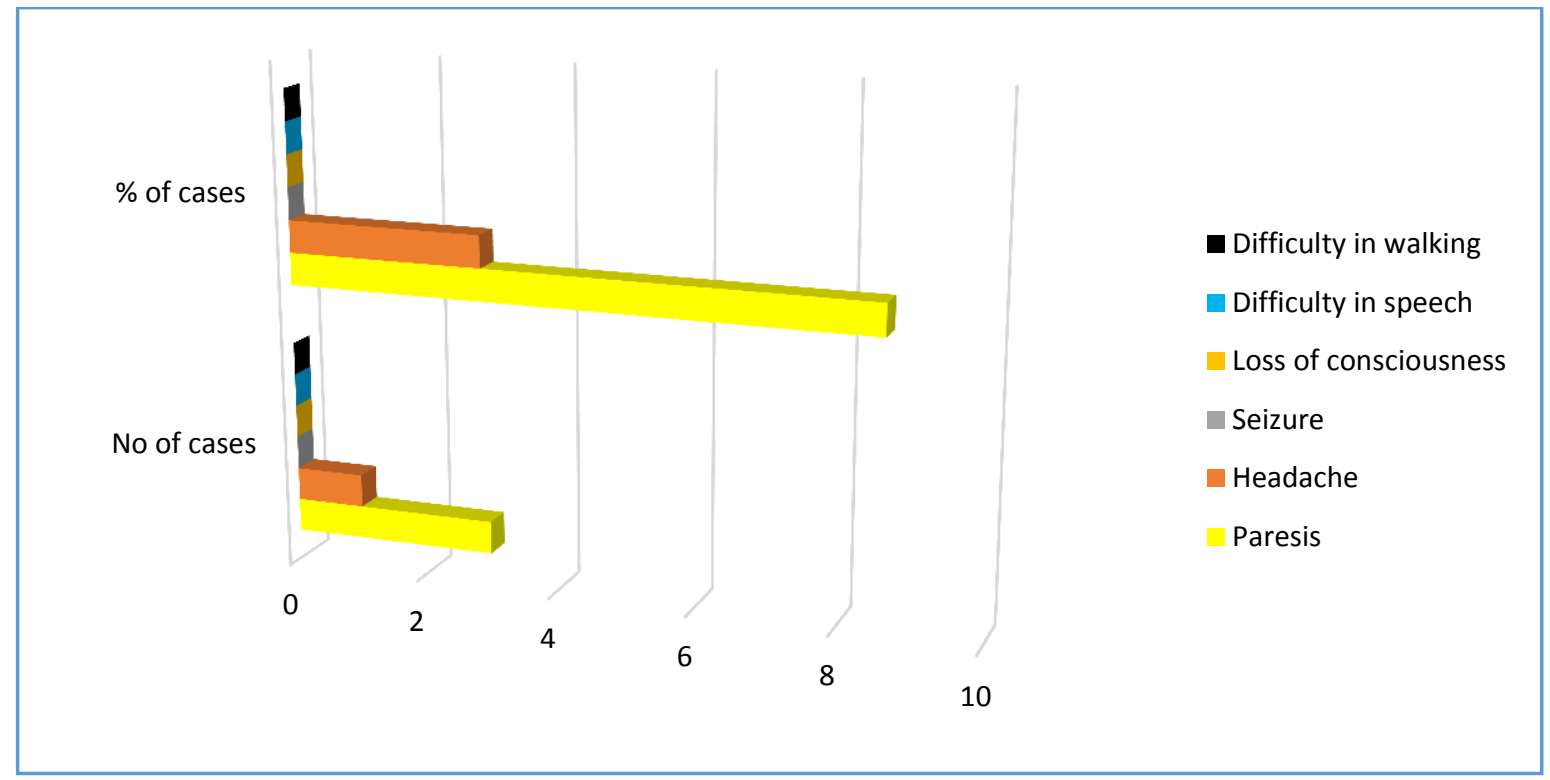

Fig. 11

Table 11: Incidence of re-exploration post burr hole evacuation

\begin{tabular}{|l|l|l|l|l|}
\hline & Cases operated & Cases explored & Outcome (Good) & Outcome (Bad) \\
\hline No of cases & 35 & 4 & 35 & 0 \\
\hline \% of cases & 100 & 11.5 & 100 & 0 \\
\hline
\end{tabular}

In our study, incidence of re-exploration immediately after burr-hole drainage was $11.5 \%$ seen in 4 out of the 35 operated cases.

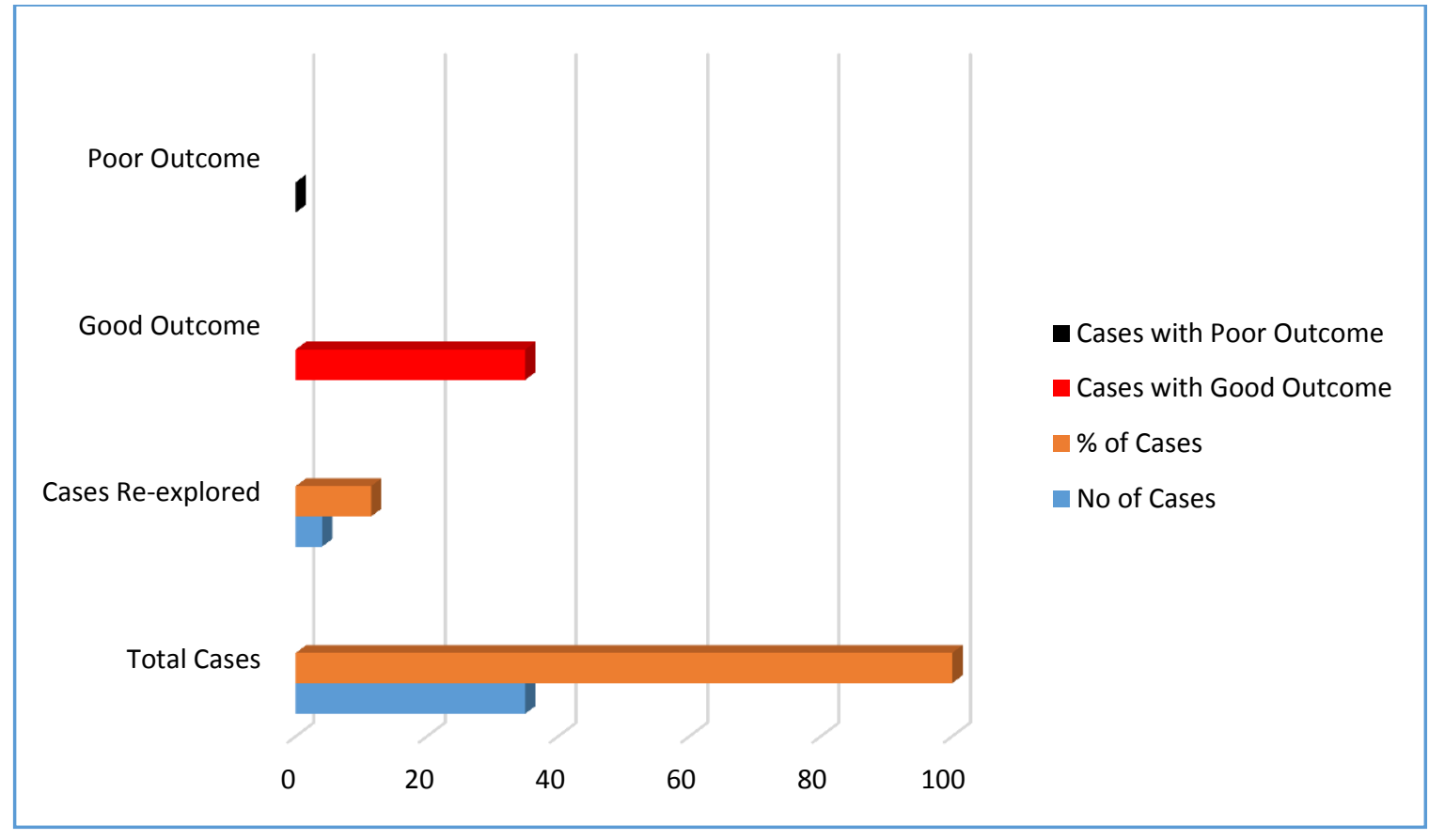

Fig. 12

Table 12: Outcome at 3 months after admission

\begin{tabular}{|l|l|l|}
\hline Outcome & No of Cases & \% of Cases \\
\hline Poor & & \\
\hline Disability & 0 & 0 \\
\hline Death & 0 & 0 \\
\hline & & \\
\hline Good & & \\
\hline Full Recovery & 35 & 100 \\
\hline
\end{tabular}

All 35 patients had a good outcome after 3 months of surgery. 


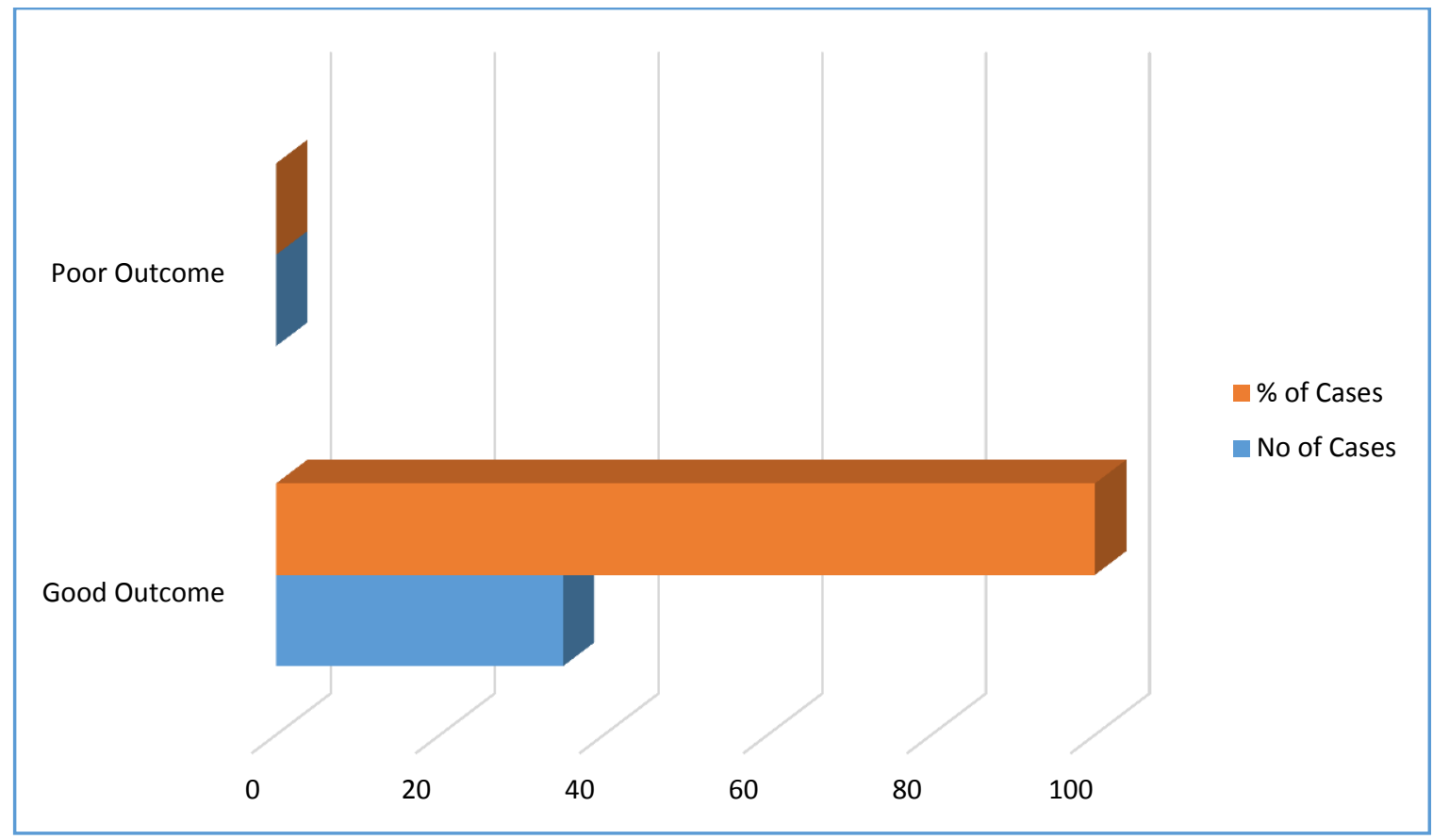

Fig. 13

\section{Discussion}

Chronic subdural hematoma is one of the most common clinical entities encountered in daily neurological practice. It occurs predominantly in elderly age group, usually after mild trauma. CT scanning has revolutionized the diagnosis and the condition is readily dealt within a neurological unit.

In our study of 35 patients of chronic subdural hematoma, 28 patients were males and 7 patients were females with a male; female ratio of $4: 1$. This is in accordance to the study conducted by Sambasivan M (1997) in which 2300 cases of chronic SDH were observed with a male; female ratio of $5: 1{ }^{43}$

The age group of the patients in our study ranged from 45 90 years with mean age of 71 years. The maximum number of patients were in the age group range of 66-70 years and 81-85 years. This is in accordance to the study conducted by Asghar M et al (2002) in which the maximum number of patients were in the age group of 65-70 years. It is concluded that Chronic SDH is a disease of the elderly. ${ }^{1}$

In our study out of the 35 cases, $20(57.14 \%)$ cases developed SDH after trauma(due to fall) and 15 (42.86\%) cases developed spontaneous SDH. This is ion discoradance to the study of O'Brien DF et al (2000) in which 123 (61.5\%) spontaneous and $77(38.5 \%)$ traumatic cases of chronic subdural hematoma were observed. $^{34}$

The most common presenting complaint of patients seen in our study was hemiplegia/hemiparesis $(74.2 \%)$ followed by headache $(42.8 \%)$. This is in discordance to the study conducted by Fogelholm R et al (1975) in which 109 patients were studied and headache was found to be the most common symptom, seen in $60 \%$ cases. $^{12}$

In our study $28.6 \%$ cases were found to have bilateral hematoma. This is in discordance to the study conducted by McKissock et al (1960) in which $15-20 \%$ cases were bilateral. ${ }^{27}$

The most common post-operative complication observed in our study was reaccumulation of hematoma seen in $4(11.4 \%)$ cases. This is in cordance to the studies conducted by Baechli wt al (2004) and Tindall et al (1976) who reported 10-15\% cases of reaccumulation of hematoma. It is concluded that reaccumulation of hematoma is the most common post-operative complication. ${ }^{2,48}$

In our study out of 35 patients $27(77.2 \%)$ had GCS score of 15 . These patients were discharged home earlier postoperatively, with good outcome. This is in accordance to the study conducted by Chen CW et al (2004) in which poor outcome was observed in patients with thick density type of lesion on CT scan. ${ }^{5}$

In our study surgical outcome was good in $100 \%$ cases. This is in accordance to the study conducted by Maurice and Williams (1999) which showed that surgical outcome was good in 90-100\% cases. $^{25}$

In our study $0 \%$ surgical mortality was observed which is in accordance to the study of Rhode et al (2002) in which <5\% surgical mortality was observed. It is concluded that surgery is the best treatment option of chronic SDH. ${ }^{40}$

In our study, the recurrence rate observed was $0 \%$. This is in discordance to the study conducted by Krupp and Jans (1995) which showed $20-30 \%$ recurrence rate. Recurrence is especially seen if fluid drainage is less than expected or pre-operative imaging studies suggest a basal layered collection. ${ }^{18}$

\section{Summary and Conclusion}

Surgical treatment of chronic subdural hematoma - Clinical characteristics, surgical outcome, complications and recurrence rate were studied during a period of 2 months between $1^{\text {st }}$ June, 2020 and $31^{\text {st }}$ July, 2020 at GMC Jammu.

The mean age of patients was 71 years, $51.4 \%$ cases belonged to age group of upto 70 years. $25.7 \%$ cases belonged to 8th decade of life and $22.9 \%$ belonged to 9 th decade of life. Youngest age group is from $46-50$ years and oldest age group is from $81-85$ years.

- Weakness of part/parts of body (74.2\%), difficulty in walking $(51.4 \%)$ and headache $(42.8 \%)$ were the most common presenting symptoms with which the patient presented to the hospital. The symptoms improved postoperatively. 
- Due to availability of investigations such as CT scan and MRI, the confirmation of diagnosis has significantly improved.

- 26 cases had fronto-parietal lesion, 4 fronto-parietotemporal lesion, 2 fronto-parieto-occipital, 2 frontotemporal and 1 frontal lesion. All patients had good postoperative outcome.

- 18 cases had $<10 \mathrm{~mm}$ thick lesion on CT scan, 12 cases had 10-20 mm thick lesion on CT and 5 patients had $>30$ mm thick lesion. 20 patients had midline shift on CT scan.

- It was concluded that the site of lesion, midline shift does not affect outcome.

- Outcome was not affected by the presence of unilateral hematoma which was seen in 25 cases or bilateral hematoma which was seen in 10 cases. Outcome was good in all the cases.

- 27 cases had GCS score of $>13$ and 8 patients had a GCS score of $<13$. All the patients had good outcome postoperatively.

- Etiology of chronic SDH did not affect the outcome whether it developed spontaneously or after trauma.

- 4 cases were re-explored due to reaccumulation of hematoma which presented with weakness and headache post burr-hole drainage.

- No recurrence was observed in our study.

$0 \%$ mortality was observed in our study.

\section{Ethical approval}

The study was approved by the Institutional Ethics Committee.

\section{List of abbreviations}

SDH - Subdural Hematoma

CSF - Cerebrospinal Fluid

CT - Computed Tomography

MRI - Magnetic Resonance Imaging

DIC - Disseminated Intravascular Coagulation

OT - Operation Theatre

GCS - Glasgow Coma Scale

\section{Conflicts of interest}

None declared

\section{Funding}

No Funding Sources

\section{Authors' contributions}

VKG performed the operative interventions. AG analyzed and interpreted the patients' data regarding the surgical management of Chronic SDH. Both the authors read and approved the final manuscript.

\section{Bibliography}

[1] Asghar M, Adhiyaman V, Greenway MW, et al (2002)., Chronic subdural haematoma in the elderly - A North Wales experience. J R Soc Med. 2002; 95(6):290-2.
[2] Baechli H, Nordmann A, Bucher HC, Gratzl O. Demographics and prevalent risk factors of chronic subdural haematoma: results of a large single-center cohort study. Neurosurg Rev. 2004;27:263-266.

[3] Bosma JJ, Miles JB, Shaw MD. Spontaneous chronic and subacute subdural haematoma in young adults. Acta Neurochir (Wien) 2000; 142:1307-10.

[4] Cameron MM. Chronic subdural haematoma:A review of 114 cases.J Neurol Neurosurg Psychiatry.1978; 41(9):834-9.

[5] Chen CW, Kuo JR, Lin HJ, et al (2004)., Early postoperative seizures after burr-hole drainage for chronic subdural hematoma: correlation with brain CT findings. $J$ Clin Neurosci. 2004 Sep;11(7):706-9.

[6] Datta S, Stoodley N, Jayawant S, et al (2005)., Neuroradiological aspects of subdural haemorrhages. Arch Dis Child. 2005; 90(9):947-51.

[7] Ducruet, Andrew F., et al. "The surgical management of chronic subdural hematoma." Neurosurgical review 35.2 (2012): 155-169.

[8] Ernestus RI, Beldzinski P, Lanfermann H, et al (1997)., Chronic subdural hematoma: surgical treatment and outcome in 104 patients. Surg Neurol. 1997 Sep; 48(3):220-5.

[9] El-Kadi H, Miele VJ, Kaufman HH. Prognosis of chronic subdural hematomas. Neurosurg Clin N Am. $2000 \mathrm{Jul}$; 11(3):553-67.

[10] Fukui S. [Evaluation of surgical treatment for chronic subdural hematoma in extremely aged (over 80 years old) patients]. No To Shinkei. 1993 May; 45(5):449-53.

[11] Fukuhara T, Gotoh M, Asari S, et al (1996)., The relationship between brain surface elastance and brain reexpansion after evacuation of chronic subdural hematoma. Surg Neurol. 1996 Jun; 45(6):570-4.

[12] Fogelholm R, Heiskanen O, Waltimo O. Chronic subdural hematoma in adults. Influence of patient's age on symptoms, signs, and thickness of hematoma. $J$ Neurosurg. 1975 Jan; 42(1):43-6.

[13] Gelabert-González M, Iglesias-Pais M, García-Allut et al., Chronic subdural haematoma: surgical treatment and outcome in 1000 cases. Clin Neurol Neurosurg. 2005 Apr; 107(3):223-9.

[14] Gjerris, F., \& Schmidt, K. (1974). Chronic subdural hematoma, Journal of Neurosurgery, 40(5), 639-42.

[15] Huang YH, Yang TM, Lin YJ, et al (2011)., Risk factors and outcome of seizures after chronic subdural hematoma. Neurocrit Care. 2011 Apr; 14(2):253-9.

[16] Horikoshi T, Naganuma H, Fukasawa I, et al (1998)., Computed tomography characteristics suggestive of spontaneous resolution of chronic subdural hematoma. Neurol Med Chir (Tokyo). 1998 Sep; 38(9):527-32; discussion 532-3.

[17] Iliescu I. A. (2015). Current diagnosis and treatment of chronic subdural haematomas. Journal of medicine and life, 8(3), 278-284.

[18] Krupp WF, Jans PJ. Treatment of chronic subdural haematoma with burr-hole craniostomy and closed drainage. Br J Neurosurg. 1995; 9(5):619-27.

[19] Kwon TH, Park YK, Lim DJ, et al (1993)., Chronic subdural hematoma: evaluation of the clinical significance of postoperative drainage volume. $J$ Neurosurg. 2000 Nov; 93(5):796-9. 
[20] Liliang PC, Tsai YD, Liang CL, et al (2002)., Chronic subdural hematoma in young and extremely aged adults: a comparative study of two age groups. Injury. 2002 May; 33(4):345-8.

[21] Lee JY, Ebel H, Ernestus RI, et al (2004)., Various surgical treatments of chronic subdural hematoma and outcome in 172 patients: is membranectomy necessary? Surg Neurol. 2004 Jun; 61(6):523-7; discussion 527-8.

[22] Lee KS, Bae WK, Doh JW, et al (1998)., Origin of chronic subdural haematoma and relation to traumatic subdural lesions. Brain Inj. 1998 Nov; 12(11):901-10.

[23] Luxon LM, Harrison MJ. Chronic subdural haematoma. Q J Med. 1979 Jan; 48(189):43-53.

[24] Markwalder TM, Seiler RW. Chronic subdural hematomas: to drain or not to drain? Neurosurgery. 1985 Feb; 16(2):185-8.

[25] Maurice-Williams RS. Chronic subdural haematoma: an everyday problem for the neurosurgeon. Br J Neurosurg. 1999 Dec; 13(6):547-9.

[26] Matsumoto K, Akagi K, Abekura M, et al (1999)., Recurrence factors for chronic subdural hematomas after burr-hole craniostomy and closed system drainage. Neurol Res. 1999 Apr; 21(3):277-80.

[27] McKissock W, Richardson A, Bloom WH. Subdural haematoma: a review of 389 cases. Lancet. 1960; 275:1365-1369.

[28] Mehta V, Harward SC, Sankey EW, et al. Evidence based diagnosis and management of chronic subdural hematoma: a review of the literature. $J$ Clin Neurosci. 2018;50:7-15.

[29] Merlicco G, Pierangeli E, di Padova PL. Chronic subdural hematomas in adults: prognostic factors. Analysis of 70 cases. Neurosurg Rev. 1995; 18(4):24751.

[30] Murata K. Chronic subdural hematoma may be preceded by persistent traumatic subdural effusion. Neurol Med Chir (Tokyo). 1993 Oct; 33(10):691-6.

[31] Naffzinger HC. Subdural fluid accumulations following head injury. JAMA. 1924; 82(22):1751-2.

[32] Nakaguchi H, Tanishima T, Yoshimasu N. Relationship between drainage catheter location and post-operative recurrence of chronic subdural hematoma after burr-hole irrigation and closed-system drainage. J Neurosurg. 2000 Nov; 93(5):791-5.

[33] Nakajima H, Yasui T, Nishikawa M, et al (2002). The role of post-operative patient posture in the recurrence of chronic subdural hematoma: a prospective randomized trial. Surg Neurol. 2002 Dec; 58(6):385-7.

[34] O'Brien DF, Basu S, O'Donnell JR, et al (2000)., The impact of aspirin therapy and anticoagulation on the prevalence of spontaneous subdural haematoma. Irish Medical Journal. 2000 Nov; 93(8):244-6.

[35] Okada Y, Akai T, Okamoto K, et al (2002). A comparative study of the treatment of chronic subdural hematoma--burr hole drainage versus burr hole irrigation. Surg Neurol. 2002 Jun; 57(6):405-9; discussion 410.

[36] Potter JF, Fruin AH. Chronic subdural hematoma - the "great imitator". Geriatrics. 1977 Jun; 32(6):61-6.
[37] Putnam TJ, Cushing H. Chronic subdural hematoma: its pathology, its relation to pachymeningititis Hemorrhagica and its surgical treatment. Arch Surg. 1925; 11(3):329-93.

[38] Ramachandran R, Hegde T. Chronic subdural hematomas - causes of morbidity and mortality. Surg Neurol. 2007 Apr; 67(4):367-72; discussion 372-3.

[39] Rauhala M, Luoto TM, Huhtala H, et al (2019) The incidence of chronic subdural hematomas from 1990 to 2015 in a defined Finnish population. J Neurosurg 1-11.

[40] Rhode V, Graf G, Hassler W. Complications of burr-hole craniotomy and closed-system drainage for chronic subdural hematomas: a retrospective analysis of 376 patients. Neurosurg Rev. 2002;25(1-2):89-94.

[41] Ridwan S, Bohrer AM, Grote A, et al (2019). Surgical treatment of chronic subdural hematoma: predicting recurrence and cure. World Neurosurg. 2019; 128:e1010-e1023.

[42] Robinson, R.G. (1984). Chronic subdural hematoma: surgical management in 133 patients, Journal of Neurosurgery, 61(2), 263-8.

[43] Sambasivan M. An overview of chronic subdural hematoma: experience with 2300 cases. Surg Neurol. 1997 May; 47(5):418-22.

[44] Soleman J, Kamenova M, Lutz K, Guzman R, Fandino J, Mariani L. Drain insertion in chronic subdural hematoma: an international survey of practice. World Neurosurg. 2017;104:528-536.

[45] Stanisic M, Lund-Johansen M, Mahesparan R. Treatment of chronic subdural hematoma by burr-hole craniostomy in adults: influence of some factors on postoperative recurrence. Acta Neurochir (Wien). 2005 Dec; 147(12):1249-56; discussion 1256-7.

[46] Sato M, Endo Y, Takahagi S, et al (1995)., [Chronic subdural hematoma with bleeding tendency; clinical analysis of 11 surgical cases]. No Shinkei geka. Neurological Surgery. 1995 Jan; 23(1):49-54.

[47] Sundstrøm T, Helland CA, Aarhus M, et al. What is the pressure in chronic subdural hematomas? A prospective, population-based study. J Neurotrauma. 2012; 29:13742.

[48] Tindall GT, Payne NS 2nd, O'Brien MS. Complications of surgery for subdural hematoma. Clin Neurosurg. 1976; 23:465-82.

[49] Tsai, Tai-Hsin MD; Lieu, et al (2010)., A Comparative Study of the Patients With Bilateral or Unilateral Chronic Subdural Hematoma: Precipitating Factors and Postoperative Outcomes, The Journal of Trauma: Injury, Infection, and Critical Care: March 2010 - Volume 68 Issue 3 - p 571-5.

[50] Traynelis VC. Chronic subdural hematoma in the elderly. Clin Geriatr Med. 1991 Aug; 7(3):583-98.

[51] Yang W, Huang J. Chronic subdural hematoma: epidemiology and natural history. Neurosurg Clin N Am. 2017;28:205-210.

[52] Zarkou S, Aguilar MI, Patel NP, et al (2009)., The role of corticosteroids in the management of chronic subdural hematomas: a critically appraised topic. Neurologist. 2009 Sep; 15(5):299-302. 